\title{
China's Health Challenges after the Yushu Earthquake
}

\author{
Haiwen Peng
}

Health Service Faculty, the Second Military Medical University, Yangpu District, Shanghai, China

Prehosp Disaster Med 2011;26(2):135-136.

Correspondence:

E-mail: penghaiwen@21cn.com

Online publication: 3 May 2011

doi: 10.1017/S1049023X11000161
The 7.1-magnitude Yushu earthquake, the second catastrophic event within two years of the 8.0-magnitude Wenchuan earthquake of 12 May 2008, left 2,220 people dead and 70 missing (all of whom are presumed dead after being buried under rubble). As of 25 April 2010, the rescue effort was ongoing.

In Rima Village, Upper Laxiu township, Yushu County, Yushu Tibetan Autonomous Prefecture (also called Yushu), Qinghai Province, China. The location lies in remote and rugged terrain, near the border of the Tibet Autonomous Region, Sichuan Province, and Qinghai Province. The epicenter is approximately $30 \mathrm{~km}$ from Jiegu Town (the seat of Yushu County and also the seat of Yushu Tibetan Autonomous Prefecture), about $240 \mathrm{~km}$ from Changdu, and about $820 \mathrm{~km}$ from Xining (the capital of Qinghai Province). The epicenter was in a sparsely populated area on the Tibetan plateau that experiences frequent earthquakes.

Its average altitude is $>4,200 \mathrm{~km}$, and the average annual temperature is $2.9^{\circ} \mathrm{C}$; the monthly temperature is $-7.5^{\circ} \mathrm{C}$ in January, and $12.5^{\circ} \mathrm{C}$ in July. Ninty percent of the population is Tibetan.

Fifty-two mobile medical teams, including 3,032 medical workers from civilian and military units, provided first aid and treatment. By 23 April, hospitals had admitted 9,145 injured people. Of them, 2,674 were evacuated to hospitals in other cities such as Xining, Chengdu Lanzhou, and Xian, because the medical system was overwhelmed in Yushu. More than 40,000 injured persons were treated in mobile medical hospitals and temporary clinics deployed by mobile medical teams.

Epidemic prevention also was an important issue. The affected area was divided into 19 task regions. A total of 308 epidemic workers responsible for disease prevention, food and water security, and environmental safety. Crews sprayed with disinfectants before and after searching the ruins. So far, there is no evidence of contagious diseases and there is no threat of food poisoning. Free food and bottled drinking water were supplied to survivors by government and rescue organizations. Water tankers also were supplied. The epidemic teams performed inspections in their respective regions. They also examined the animals, because zoonosis was a risk.

Rescue workers were forced to cope with altitude sickness. Since Yushu is located at an average altitude of 4,200 meters, partial pressure of oxygen is much less than at sea level. Batang Airport, the only airport in Yushu, has an altitude of 3,900 meters, and served as the first station for outside rescuers. Many rescuers from the lowlands became due to altitude sickness. Thirty-five rescuers belonging to the Guangdong Fire Corps and Beijing Fire Corps suffered severe pulmonary edema or cerebral edema and were evacuated to a hospital at a lower altitude in Xian. Approximately 300 remaining members of the Guangdong Fire Corps returned to Guangdong by 19 April. One Chinese reporter evacuated to Lanzhou (the capital of Gansu Province) was confirmed dead on 18 April due to pulmonary complications. Many rescue teams from lowlands such as Guangxi, Hubei, and Sichuan that were deployed in Yushu returned to Xining by 19 April because of altitude sickness. Many sniffer dogs also had to leave the area.

Communication problems also were encountered. The Tibetan area was affected by the earthquake. The ethnic Tibetan people have their own unique language, culture, and religion. As doctors examined and diagnosed the injured, patients and care providers could not understand each other. Volunteers who understand both languages interpret between doctors and the injured. A 10-year-old Tibetan boy worked as an interpreter 
in a temporary hospital in Jiegu Town for several days after his house collapsed in the earthquake.

The local temples played an important role in managing corpses. In Jiegu Town, local survivors delivered their dead relatives to the Jiegu Temple. The monks (Lama) held a religious ceremony before cremation. More than 1,300 corpses were cremated on 17 April. If not for the disaster, relatives and lamas would have held a celestial burial for the dead. During this burial, vultures would eat the entire body, leaving no remains.
With so many corpses, incineration was the only method that all people could accept from a religious, traditional, and healthcare point of view.

The psychological damage was harder to quantify, but with religion, most Tibetan people show calmness facing death. Psychological assistance was performed silently.

Power, the water supply, and communications are now restored. Students went back to tent schools. Reconstruction will take approximately five years. 